\title{
Spontaneous ventilation thoracic surgery-to follow the Hippocratic Oath
}

\begin{abstract}
"Nil nocere!" As the ancient sentence from the Hippocratic Oath tells us, in every medical and surgical intervention, the most important thing is to cause the least harm to the patient. As we know, every surgery induces surgical stress, which attenuates the self-defense system of the patient, including the immune function. Surgeons eventually realized this mechanism, prompting the identification and evolution of procedures that could, for the most part, maintain the normal homeostasis of the patient. From the surgical side, the first step towards this end was the replacement of the open thoracotomy with video-assisted thoracic surgery in approximately $70 \%$ of the interventions. Subsequently, in order to reduce anesthetic stress, spontaneous ventilation during thoracic surgery was applied to supplement the surgical advantages. With the use of spontaneous ventilation, particularly spontaneous one lung ventilation, the negative effects of mechanical one lung ventilation, such as volutrauma/barotrauma, biotrauma, and the inflammatory response, can be reduced or ceased. The advantages of spontaneous ventilation thoracic surgery are clearly observed with a decrease in postoperative complications, such as a lower incidence of postoperative pneumonia, shorter hospital stay, and more active patients after lung surgery.

Basic knowledge regarding spontaneous ventilation thoracic surgery is summarized in this series. Because the terminology of spontaneous ventilation is currently not harmonized in the literature (i.e., non-intubated thoracic surgery, awake thoracic surgery, spontaneous ventilation thoracic surgery, tubeless thoracic surgery), we used non-intubated thoracic surgery (NITS) to refer to the intervention performed with spontaneous ventilation.
\end{abstract}

One of the articles introduces the "Essentials of the NITS." This is an overview of the NITS technique in everyday practice.

You can also find an article on the immune background and response to NITS. After reading this very detailed article, the emerging question is this: What is the impact of NITS on the immunotherapy of operated lung cancer patients?

The anesthesiological part summarizes all the techniques that are currently used for NITS. Why do I eagerly recommend this part? To be frank, anesthesia is the key to success in NITS.

After getting to know the current state-of-the-art techniques in the performance of major lung resections with spontaneous ventilation, the possibilities of NITS appear to be almost unlimited. This part summarizes the currently performed NITS major lung resections.

One of the most promising parts is NITS thymectomy. I am definite that, in the near future, NITS thymectomy will be the standard procedure for myasthenia gravis patients.

I hope this series about non-intubated thoracic surgery meets your interest.

\section{Acknowledgments}

Funding: None.

\section{Footnote}

Provenance and Peer Review: This article was commissioned by the editorial office, AME Surgical fournal for the series "Spontaneous Ventilation Thoracic Surgery". The article did not undergo external peer review.

Conflicts of Interest: The author has completed the ICMJE uniform disclosure form (available at https://asj.amegroups.com/ article/view/10.21037/asj-21-113/coif). The series "Spontaneous Ventilation Thoracic Surgery" was commissioned by the editorial office without any funding or sponsorship. JF served as an unpaid Guest Editor of the series and serves as an unpaid 
editorial board member of AME Surgical fournal from January 2021 to December 2022. The author has no other conflicts of interest to declare.

Ethical Statement: The author is accountable for all aspects of the work in ensuring that questions related to the accuracy or integrity of any part of the work are appropriately investigated and resolved.

Open Access Statement: This is an Open Access article distributed in accordance with the Creative Commons AttributionNonCommercial-NoDerivs 4.0 International License (CC BY-NC-ND 4.0), which permits the non-commercial replication and distribution of the article with the strict proviso that no changes or edits are made and the original work is properly cited (including links to both the formal publication through the relevant DOI and the license). See: https://creativecommons.org/ licenses/by-nc-nd/4.0/.

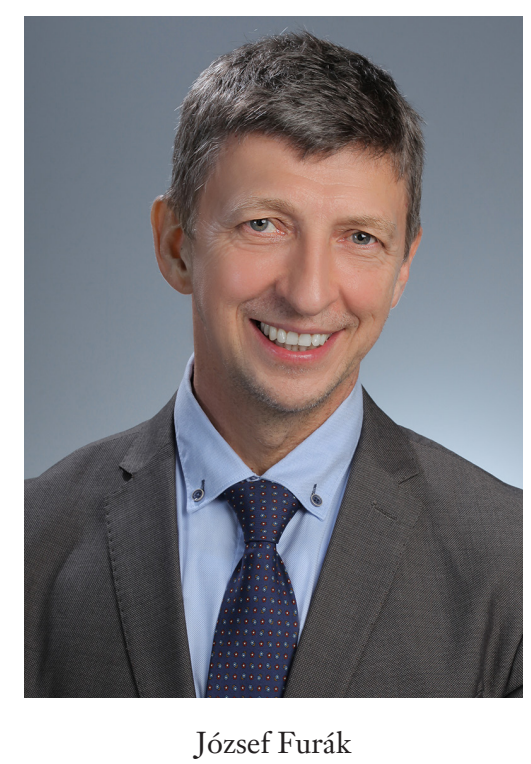

József Furák

Division of Thoracic Surgery, Department of Surgery, University of Szeged, Szeged, Hungary.

(Email:jfurak@gmail.com)

Received: 25 November 2021; Accepted: 09 December 2021; Published: 30 June 2022.

doi: $10.21037 /$ asj-21-113

View this article at: https://dx.doi.org/10.21037/asj-21-113

doi: $10.21037 /$ asj-21-113

Cite this article as: Furák J. Spontaneous ventilation thoracic surgery-to follow the Hippocratic Oath. AME Surg J 2022;2:11. 